\title{
Pulmonary nodular lymphoid hyperplasia in a 53-year-old man with malignant sign: a case report
}

\author{
Zhen Yang ${ }^{1}$, Lianshuang Wei ${ }^{2}, \mathrm{Xu} \mathrm{Li}^{1}$ and Xin Liu ${ }^{1^{*}}$ (1)
}

\begin{abstract}
Background: Pulmonary nodular lymphoid hyperplasia (PNLH) is a rare benign illness. Due to atypical clinical and radiographic presentations, diagnosis largely depends on postoperative pathological examination. Thus, preoperative misdiagnosis is often occurred.

Case presentation: We present a case of asymptomatic PNLH that was seen as ground-glass opacity (GGO) on computed tomography (CT). After 3-year observation, the diagnosis tends to adenocarcinoma owing to increasing density of the node and vessel convergence sign, which were signs of malignancy. Video-assisted segmentectomy (S10) was carried out. Histopathologic examination of postoperative specimen showed follicular lymphoid hyperplasia with interfollicular lymphoplasmacytosis, consistent with PNLH. The follow-up chest CT images showed no recurrence or metastasis.
\end{abstract}

Conclusion: Although it is a benign disease, PNLH can exhibit malignant signs in the imaging examinations, which could lead to misdiagnosis. This reminds us of the uncertainty between imaging findings and diagnosis. The diagnosis depends on postoperative pathological examination. Volume doubling time is a potential parameter to differentiate PNLH from lung cancer.

Keywords: Pulmonary nodular lymphoid hyperplasia, Malignant signs, Misdiagnosis, Volume doubling time, Case report

\section{Background}

Pulmonary nodular lymphoid hyperplasia (PNLH) is a rare benign disorder of the lungs, which was initially proposed known as "pseudolymphoma" in 1983, only a few dozens of cases have been reported since then. The clinical and radiographic presentations can be atypical, thus, misdiagnosis may occur before surgery. In the study, we report a case misdiagnosed as adenocarcinoma because of malignant signs in the $\mathrm{CT}$ scan, however, it identified

\footnotetext{
*Correspondence: 13629441520@163.com

1 Department of Thoracic Surgery, The Second Affiliated Hospital

of Kunming Medical University, 374th Dianmian Road, Kunming, Yunnan Province, China

Full list of author information is available at the end of the article
}

as PNLH by the pathologic findings after operation. It reminds us of the uncertainty between imaging findings and diagnosis. Surgical resection is not only diagnostic but also curative.

\section{Case presentation}

A 53-year-old man was transferred from a local hospital after undergoing a routine health examination. He was healthy with no obvious discomfort, and he had 40 pack years smoking history. The initial chest CT scan performed in July 2017 revealed a GGO measuring up to $1.6 \mathrm{~cm}$ in maximum diameter and $2.14 \mathrm{~cm}^{3}$ in volume in the lower lobe of the left lung (Fig. 1a). The GGO was multifocal, suggesting that it was likely original author(s) and the source, provide a link to the Creative Commons licence, and indicate if changes were made. The images or other third party material in this article are included in the article's Creative Commons licence, unless indicated otherwise in a credit line to the material. If material is not included in the article's Creative Commons licence and your intended use is not permitted by statutory regulation or exceeds the permitted use, you will need to obtain permission directly from the copyright holder. To view a copy of this licence, visit http://creativecommons.org/licenses/by/4.0/. The Creative Commons Public Domain Dedication waiver (http://creativeco mmons.org/publicdomain/zero/1.0/) applies to the data made available in this article, unless otherwise stated in a credit line to the data. 

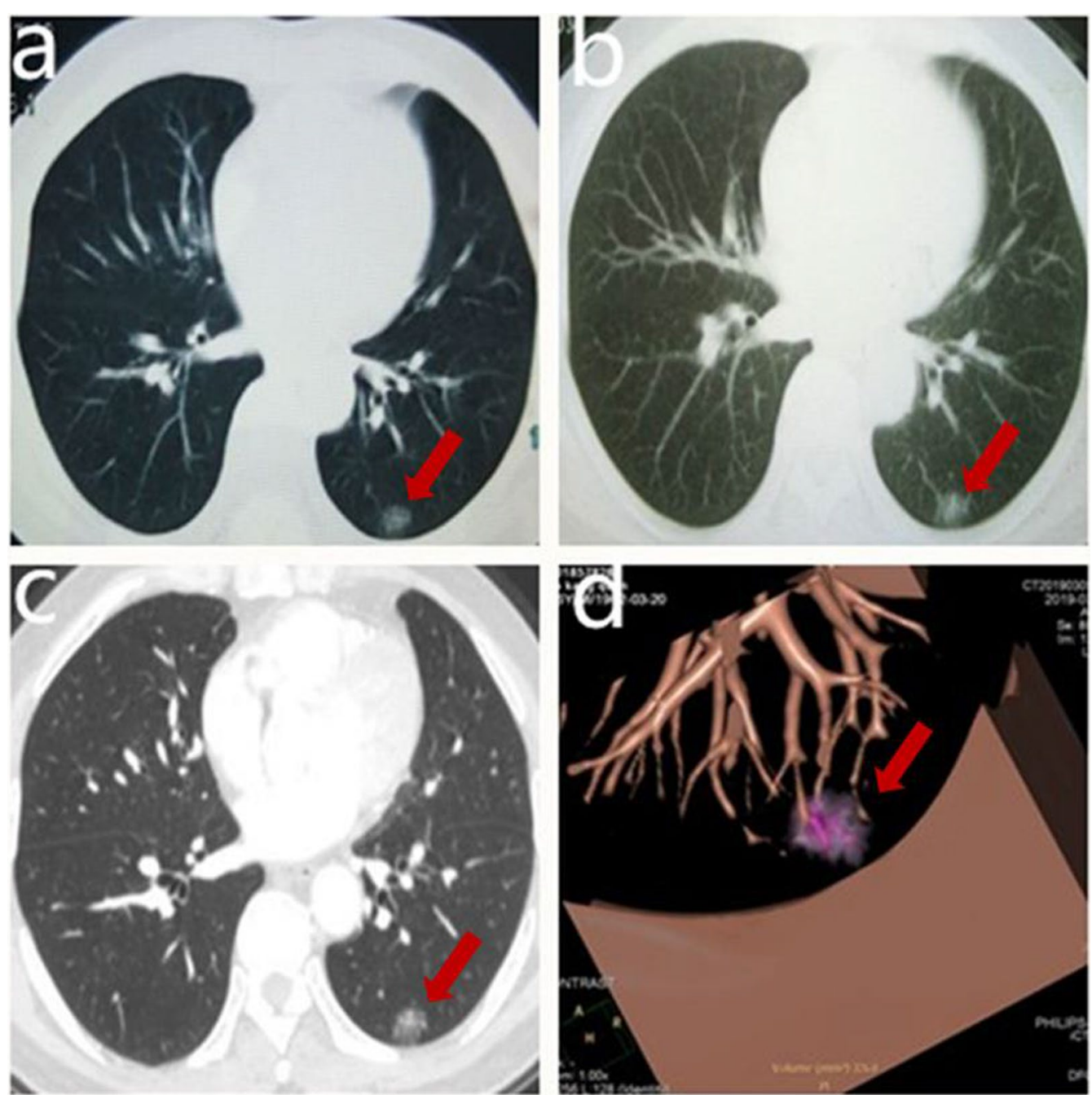

Fig. 1 The CT scan of the patient. a Initial CT scan performed in July 2017. b Follow-up CT scan performed in November 2018. c Follow-up CT scan performed March 2019. d The three-dimensional reconstruction of CT scan performed in March 2019

a chronic lesion. A follow-up chest CT scan was performed 16 months later, and no interval change was found (Fig. 1b).

Another CT scan performed 20 months later in March 2019 showed density of the GGO increasing (Fig. 1c) and vessel convergence emerging (Fig. 1d), which were signs of malignancy. While the maximum diameter was $1.7 \mathrm{~cm}$ and volume was $2.57 \mathrm{~cm}^{3}$ in CT scan. Adenocarcinoma seemed to be the most likely diagnosis, followed by AAH. While the maximum diameter and volume of the lesion remained relatively stable. Video-assisted segmentectomy (S10) and lymph node samplings were carried out in March 2019. The resected lung tissue measured $6 \times 2.5 \times 1 \mathrm{~cm}$, and an ill-defined grayish solid nodule measured $1.2 \times 1.1 \times 0.8 \mathrm{~cm}$ was included. No malignant cells were found on intraoperative frozen section examination. Histopathologic examination showed follicular lymphoid hyperplasia with interfollicular lymphoplasmacytosis, consistent with PNLH. The immunohistochemical results showed positivity for CD3, CD20, CD38, CD45RO, CD68, CD138, PAX-5, and Bcl-6, and negativity for CD23 and Bcl-2 (Fig. 2). No mediastinal lymph node metastasis was found in the specimens.

The patient recovered and discharged 4 days after surgery without any complications. He was diagnosed as PNLH, and subsequently followed-up with chest CT scans regularly. The scans showed no recurrence or metastasis, and the patient did not have any further discomfort, which indicated 48-month follow-up outcome was excellent. Long-term follow-up will be continued. 


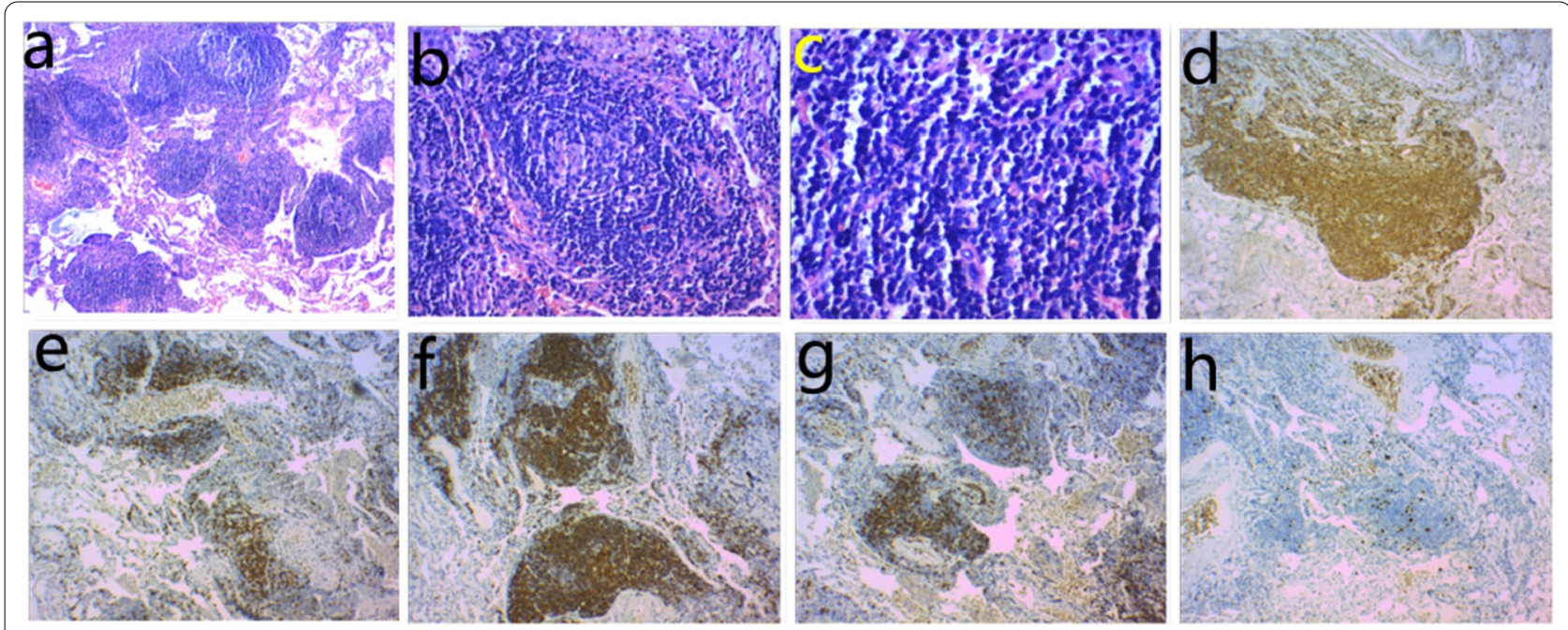

Fig. 2 Histopathologic and immunohistochemical result. a Reactive germinal centers. b Germinal center cells. c A mixture of polyclonal B, T lymphocytes and plasma cells. d Bcl-6 immunostaining. e CD3 immunostaining. f CD60 immunostaining. $\mathbf{g}$ CD45R0 immunostaining. $\mathbf{h}$ Ki67 immunostaining

\section{Discussion}

Pulmonary nodular lymphoid hyperplasia is a reactive lymphadenia, composed of reactive nodular lymphoid proliferation that formed one or more pulmonary masses, usually asymptomatic [1]. No gender-based differences were found in PNLH patients, and most of them were middle-aged and elderly, with the age ranging from 25 to 72 years [2]. PNLH is a rare benign disorder of the lungs, since its discovery, only a few dozen cases have been reported. Thus far, the largest study on PNLH with 67 patients was reported by Likui et al. [2].The specific etiology of PNLH is still not established, although it could be the local bronchial mucosa-related lymphoid tissue's response to potential antigenic stimulation. It may also be associated with combined variable immunodeficiency or Sjögren syndrome and granulomatouslymphocytic interstitial lung disease such as IgG4-related sclerosing diseases [3]. In addition, Bégueret et al. highlighted that smoking may also be an important risk factor for PNLH [4].

Because of the rarity, radiological findings can only be gathered from case reports and radiographic descriptions. CT scans show a unique $2-4-\mathrm{cm}$ nodule in most cases, which could be solitary, or multi-nodular, solid, or subsolid, and occasionally with lobulation, vessel convergence, pleural indentation, and mediastinal or hilar lymph node involvement [3], moreover, some authors presented a case of PNLH with positive fluorodeoxyglucose (FDG) uptaking [5]. With these signs of malignancy, lung cancer is the first suspected diagnosis. Thus, misdiagnosis can also occur before pathological examination. Histologically, PNLH is composed of well-defined lymphoid tissue masses with numerous reactive germinal centers, interfollicular lymphocytes, and plasma cells, and is mainly located in the subpleural area. Immunohistochemically, CD3-positive T cells and CD138-positive plasma cells are reactive in the interfollicular zone; whereas, CD20-positive B expresse within CD21-positive follicular dendritic cell meshworks, and do not express $\mathrm{Bcl}-2$ [3]. Our report is in accord with the study above, so PNLH is the diagnosis, in addition, CD20, CD38, CD45RO, CD68, PAX-5, and Bcl-6 were positive, while CD23 was negative, which deserve further study.

Surgical resection is not only diagnostic but also curative. Thus far, although a case suggested the possibility of spontaneous regression of the remaining lesions after resection of the PNLH lesion [6], and a case reported antibiotic-induced reduction of abnormal lung shadow in PNLH [7], few evidence thus far has suggested that PNLH could regress without operation. The surgical approach include lobectomy and sublobar resection; the latter was found suitable to treat PNLH owing to its advantages of enhanced recovery after surgery (ERAS) and preferable long-term outcome [2]. The trail No. JCOG0802/WJOG4607L suggested that segmentectomy is a potentially standard surgical approach for the lung tumor with maximum diameter $\leq 2 \mathrm{~cm}$ and consolidation tumor ratio $>0.5$ [8], so we chose segmentectomy, and the 48-month follow-up outcome was excellent. The scans showed no recurrence or metastasis, and the patient had no complaints. Long-term follow-up will be continued.

In our case, the lesion emerged as mixed ground-glass opacity, and presented malignant characteristics including increasing density and the vessel convergence sign 
after follow-up visit, which misled us to diagnose the condition as cancerous before operation. However, during the 20-month watching and waiting period, the maximum diameter and volume of the lesion remained relatively stable, the volume doubling time was 2427 days by calculating with the formula VDT $=\left(\mathrm{t}^{*} \log 2\right) /(\log [\mathrm{Vt} /$ V0]) [9]. Tumor doubling time less than 400 days represents malignant potential [10], in our case the volume doubling time is far more than 400 days, so we deduce the disease is a indolent lesion and volume doubling time is a potential parameter to differentiate PNLH from lung cancer. The assumption is necessary to be validated in a large and reliable dataset.

\section{Conclusion}

Although it is a benign disease, PNLH can exhibit malignant signs in the imaging examinations, which could lead to misdiagnosis. This reminds us of the uncertainty between imaging findings and diagnosis. The diagnosis depends on postoperative pathological examination. Volume doubling time is a potential parameter to differentiate PNLH from lung cancer.

\section{Abbreviations}

PNLH: Pulmonary nodular lymphoid hyperplasia; GGO: Ground-glass opacity; $\mathrm{CT}$ : Computed tomography.

\section{Acknowledgements}

Not applicable.

\section{Authors' contributions}

$Z Y, X L(X u L i)$ and $X L$ (Xin Liu) participated in the clinical treatments and performed the surgery. ZY and LW collected and analyzed the data. $X \mathrm{~L}(X \mathrm{U}$ $\mathrm{Li}$ ) and $\mathrm{XL}$ (Xin Liu) participated in revising the manuscript. LW provided the pathology and image figures. All authors read and approved the manuscript.

\section{Funding}

The study was supported by grants from the Health Commission of Yunnan Province Training plan for Medical Reserve Talents (grant NO.H-2018027). In addition to funding, the funding body didn't participate in the design of the study and collection, analysis, and interpretation of data and in writing the manuscript.

\section{Availability of data and materials}

The datasets used and/or analyzed in the current article are available from the corresponding author on reasonable request.

\section{Declarations}

Ethics approval and consent to participate

The case is presented anonymously, and patient consent and hospital approval have been obtained for publication.

\section{Consent for publication}

Verbal informed consent was obtained from the patient for publication of this case report and accompanying images.

\section{Competing interests}

The authors declare that they have no competing interests.

\section{Author details}

${ }^{1}$ Department of Thoracic Surgery, The Second Affiliated Hospital of Kunming Medical University, 374th Dianmian Road, Kunming, Yunnan Province, China. ${ }^{2}$ Department of Pathology, De Hong Zhou Ren Ming Yi Yuan, 13th Yonghan Street, Manshi 678400, China.

Received: 24 June 2021 Accepted: 27 September 2021

Published online: 09 October 2021

\section{References}

1. Sim J, Koh HH, Choi S, Chu J, Kim TS, Kim H, Han J. Pulmonary nodular lymphoid hyperplasia with mass-formation: clinicopathologic characteristics of nine cases and review of the literature. J Pathol Transl Med. 2018;52(4):211-8. https://doi.org/10.4132/jptm.2018.04.27.

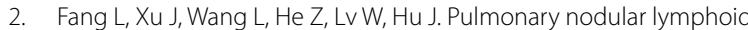
hyperplasia: a rare benign disease with malignant mask. Ann Transl Med. 2019;7(4):43. https://doi.org/10.21037/atm.2018.12.59.

3. Yell M, Rosado FG. Pulmonary nodular lymphoid hyperplasia. Arch Pathol Lab Med. 2019;143(8):1149-53. https://doi.org/10.5858/arpa. 2018-0188-RS.

4. Bégueret $H$, Vergier $B$, Parrens $M$, Parrens $M$, Lehours $P$, Laurent $P$, Vernejoux J, Dubus P, Velly J, Mégraud F, Taytard A, Merlio J, Mascarel A. Primary lung small B-celllymphoma versus lymphoid hyperplasia: evaluation of diagnostic criteria in 26cases. Am J Surg Pathol. 2002;26(1):76-81. https://doi.org/10.1097/00000478-200201000-00009.

5. Yilmaz U, Unsal I, Halilcolar H, Anar C, Yildirim Y, Sanli A, Kargi A. Nodular lymphoid hyperplasia of the lung: the role of positron emission tomography in diagnosis. Tuberk Toraks. 2009;57(4):417-21.

6. Miyoshi S, Hamada H, Katayama H, Hamaguchi N, Irifune K, Ito R, Ohtsuki Y, Yoshino T, Higaki J. A case of pulmonary nodular lymphoid hyperplasia with a resected cavity, followed by spontaneous regression of the remaining lesions. Intern Med. 2010;49(15):1617-21. https://doi.org/10. 2169/internalmedicine.49.3487.

7. Tanino A, Tsubata Y, Hamaguchi S, Sutani A, Nagase M, Isobe T. Antibioticinduced reduction of abnormal lung shadow in pulmonary nodular lymphoid hyperplasia. Respirol Case Rep. 2020;8(2): e00522. https://doi. org/10.1002/rcr2.522.

8. Eguchi T, Sato T, Shimizu K. Technical advances in segmentectomy for lung cancer: a minimally invasive strategy for deep, small, and impalpable tumors. Cancers. 2021;13(13):3137. https://doi.org/10.3390/cancers131 33137.

9. Setojima Y, Shimada Y, Tanaka T, Shigefuku S, Makino Y, Maehara S, Hagiwara M, Masuno R, Yamada T, Kakihana M, Ohira T, Ikeda N. Prognostic impact of solid-part tumour volume doubling time in patients with radiological part-solid or solid lung cancer. Eur J Cardiothorac Surg. 2020;57(4):763-70. https://doi.org/10.1093/ejcts/ezz305.

10. Obayashi K, Shimizu K, Nakazawa S, Nagashima T, Yajima T, Kosaka T, Atsumi J, Kawatani N, Yazawa T, Kaira K, Mogi A, Kuwano H. Prognostic impact of a ground glass opacity component in clinical stage IA nonsmall cell lung cancer. JThorac Dis. 2018;10(9):5428-34. https://doi.org/ 10.21037/jtd.2018.08.118.

\section{Publisher's Note}

Springer Nature remains neutral with regard to jurisdictional claims in published maps and institutional affiliations. 